\title{
Protein Phosphatase-1 Regulation in the Induction of Long-Term Potentiation: Heterogeneous Molecular Mechanisms
}

\author{
Patrick B. Allen, ${ }^{1}$ Øivind Hvalby, ${ }^{2}$ Vidar Jensen, ${ }^{2}$ Michael L. Errington, ${ }^{4}$ Mark Ramsay, ${ }^{5}$ Farrukh A. Chaudhry, ${ }^{3}$ \\ Timothy V. P. Bliss, ${ }^{4}$ Jon Storm-Mathisen, ${ }^{3}$ Richard G. M. Morris, ${ }^{5}$ Per Andersen, ${ }^{2}$ and Paul Greengard ${ }^{1}$ \\ ${ }^{1}$ Laboratory of Molecular and Cellular Neuroscience, The Rockefeller University, New York, NY 10021, ${ }^{2}$ Department of \\ Physiology and ${ }^{3}$ Anatomical Institute, Institute of Basic Medical Sciences, University of Oslo, Blindern, N-0317 Os/o, \\ ${ }^{4}$ Division of Neurophysiology, National Institute for Medical Research, London NW7 1AA, United Kingdom, ${ }^{5}$ Center for \\ Neuroscience, University of Edinburgh, Edinburgh EH8 9LE, United Kingdom
}

Protein phosphatase inhibitor-1 (I-1) has been proposed as a regulatory element in the signal transduction cascade that couples postsynaptic calcium influx to long-term changes in synaptic strength. We have evaluated this model using mice lacking I-1. Recordings made in slices prepared from mutant animals and also in anesthetized mutant animals indicated that long-term potentiation (LTP) is deficient at perforant path-dentate granule cell synapses. In vitro, this deficit was restricted to synapses of the lateral perforant path. LTP at Schaffer collateral-CA1 pyramidal cell synapses remained normal. Thus, protein phosphatase-1-mediated regulation of NMDA receptordependent synaptic plasticity involves heterogeneous molecular mechanisms, in both different dendritic subregions and different neuronal subtypes. Examination of the performance of I-1 mutants in spatial learning tests indicated that intact LTP at lateral perforant path-granule cell synapses is either redundant or is not involved in this form of learning.

Key words: synaptic plasticity; LTP; phosphoprotein phosphatase-1 (PP-1); inhibitor-1 (I-1); CA1 pyramidal cells; dentate granule cells; perforant path; spatial learning
Stable changes in synaptic strength can be observed after a range of stimuli in both intact animals and in vitro preparations. This plasticity is a candidate mechanism for information storage that might contribute to learning and memory formation (Bliss and Collingridge, 1993). Recently, attempts have been made to provide additional insight into the physiological significance of synaptic plasticity by elucidating and manipulating the underlying biochemical mechanisms. From a wide array of studies, it has become apparent that enzymes controlling protein phosphorylation at the synapse are important for the induction and maintenance of long-term changes in synaptic strength (for review, see Tokuda and Hatase, 1998). Among the enzymes involved, phosphoprotein phosphatase-1 (PP-1), a serine/threonine phosphatase, has emerged as a prominent regulatory element. PP-1 is a multifunctional enzyme that controls the phosphorylation status and activity of a variety of downstream effector molecules that are known to govern synaptic strength (Greengard et al., 1999). These include NMDA (Blank et al., 1997; Snyder et al., 1998) and AMPA (Yan et al., 1999) glutamate receptors, plus additional components of the calcium signaling cascade, such as calciumcalmodulin-dependent protein kinase II (Strack et al., 1997) and cAMP response element-binding protein (Bito et al., 1996). PP-1 is highly enriched in dendritic spines and is therefore appropriately localized for the regulation of excitatory synaptic transmission (Ouimet et al., 1995).

Various pharmacological agents can be used to inhibit PP-1 catalytic activity, and these drugs have been exploited to demon-

Received Dec. 10, 1999; revised Jan. 28, 2000; accepted Feb. 25, 2000.

This work was supported by United States Public Health Service Grants MH 40899 and DA 10044. We thank Peter Ingrassia for assistance with the mouse colony.

Correspondence should be addressed to Patrick B. Allen, Laboratory of Molecular and Cellular Neuroscience, The Rockefeller University, 1230 York Avenue, New York, NY 10021. E-mail: allenp@rockvax.rockefeller.edu.

Copyright (C) 2000 Society for Neuroscience 0270-6474/00/203537-07\$15.00/0 strate a role for PP-1 in controlling synaptic strength. In CA1 pyramidal cells, active PP-1 contributes to the induction of longterm depression (LTD) (Mulkey et al., 1994), whereas inhibition of PP-1 promotes long-term potentiation (LTP) induction (Blitzer et al., 1995, 1998). These studies also implied a physiological role for the PP-1 regulatory protein inhibitor-1 (I-1), providing support for a widely cited theoretical model that had been proposed to account for the observed changes in synaptic strength (Lisman, 1989). As a part of this model, calcium influx after NMDA receptor stimulation controls the phosphorylation state and activity of I-1; intense synaptic stimulation is predicted to preferentially activate calcium-calmodulin-dependent adenylyl cyclase, producing an increase in cAMP levels, activation of PKA, and phosphorylation of I-1. This leads to PP-1 inhibition, thereby removing opposition to the actions of calcium-activated kinases. In this study, we test the physiological role played by endogenous I-1 in the PP-1-mediated regulation of LTP induction at excitatory synapses in CA1 and in the dentate gyrus. We find that synapses differ in their sensitivity to the contribution made by I-1, indicating that additional PP-1 regulatory elements are likely to be important for synaptic plasticity.

\section{MATERIALS AND METHODS}

Gene targeting. Murine I-1 clones were isolated from a $129 \mathrm{SvJ}$ strain genomic library (Stratagene, La Jolla, CA) using a rat cDNA (Elbrecht et al., 1990) as a probe. Characterization of the locus revealed an $87 \mathrm{bp}$ exon containing the initiating methionine. Using convenient restriction sites, genomic sequence surrounding this exon was spliced into the targeting vector pPNT (Tybulewicz et al., 1991). Part of the first intron sequence $(1.5 \mathrm{~kb})$ and $5.5 \mathrm{~kb}$ of the sequence upstream of exon 1 were placed on either side of a neo cassette. The targeting vector was transfected into the E14 embryonic stem cell line (Thompson et al., 1989) by electroporation, followed by G418 (Life Technologies, Gaithersburg, MD) selection of clones. Two clones identified as positive for homologous recombination by Southern blotting were injected into blastocysts to produce chimeric 
animals. These were mated to $\mathrm{C} 57 \mathrm{Bl} / 6 \mathrm{~J}$ (The Jackson Laboratory, Bar Harbor, ME) females, and the heterozygous offspring were mated to generate mutant and wild-type mice. For the electrophysiology experiments, mutants derived from both targeted embryonic stem cell clones were used. In addition, one of these lines was backcrossed onto the $\mathrm{C} 57 \mathrm{Bl} / 6 \mathrm{~J}$ background for three and six generations, and mice from these populations were used for further electrophysiology and behavioral experiments, respectively. No differences were observed between the two lines or between the three generations of mice used for electrophysiology. All experiments were performed on male mice according to animal care guidelines.

Anatomical studies. Wild-type and littermate mutant mice were deeply anesthetized with pentobarbital (Rikshospitalets Apotek, Oslo, Norway) and perfused through the left cardiac ventricle with $2 \mathrm{ml}$ of $150 \mathrm{~mm}$ $\mathrm{NaCl}$, followed by $50 \mathrm{ml}$ of formaldehyde (freshly depolymerized from paraformaldehyde; TAAB, Reading, UK) in $0.1 \mathrm{M}$ sodium phosphate buffer, $\mathrm{pH} 7.4(\mathrm{NaPi})$. One mutant and one wild-type mouse were perfused with $4 \%$ formaldehyde, and the brain was sectioned using a Vibratome (Technical Products International, Oxford, UK) at $50 \mu \mathrm{m}$ coronally; another pair was perfused with $1 \%$ formaldehyde and sectioned horizontally. Sections were processed free-floating at room temperature $\left(\sim 22^{\circ} \mathrm{C}\right)$ through the following: NaPi rinse; $1 \mathrm{M}$ ethanolamine$\mathrm{HCl}$ in $\mathrm{NaPi}$ (30 min); $3 \%$ newborn calf serum (NCS) in TBS $(50 \mathrm{~mm}$ Tris- $\mathrm{HCl}, \mathrm{pH} 8.0$, and $150 \mathrm{~mm} \mathrm{NaCl}$ ) (30 min); affinity-purified antibody G-187 to I-1, final Ig concentration of $110-180 \mathrm{ng} / \mathrm{ml}$ (with $0.5 \%$ Triton $\mathrm{X}-100$ ) or $180-280 \mathrm{ng} / \mathrm{ml}$ (without Triton) diluted in TBS containing $1 \%$ NCS (overnight); TBS rinse; anti-rabbit Ig biotinylated species-specific whole antibody from donkey (Amersham Pharmacia Biotech, Buckinghamshire, UK) diluted 1:100 in TBS (90 min); TBS rinse; streptavidinbiotinylated horseradish peroxidase complex (Amersham Pharmacia Biotech) diluted 1:100 in TBS (90 min); TBS rinse; Tris- $\mathrm{HCl}$ rinse; diaminobenzidine $0.5 \mathrm{mg} / \mathrm{ml}$ in Tris- $\mathrm{HCl} 50 \mathrm{~mm}$, pH 7.6 (6 min); same plus $0.01 \mathrm{mg} / \mathrm{ml} \mathrm{H}_{2} \mathrm{O}_{2}(9 \mathrm{~min})$; Tris- $\mathrm{HCl}$ rinse; and mounting in glycerol-gelatin. Triton X-100 was added to the TBS for optimum penetration of antibodies to reveal the regional distribution of I-1 (see Fig. $2 A, B$ ) but was omitted for better resolution of cytological details (see Fig. $2 C-E$ ). For electron microscopy, tissue processed without Triton was post-fixed with $\mathrm{OsO}_{4}$, dehydrated in ethanol, embedded in Durcupan ACM (Fluka, Buchs, Switzerland), sectioned, and contrasted with lead and uranyl. The antibody was affinity-purified on recombinant I-1 coupled to Sepharose (Amersham Pharmacia Biotech, Uppsala, Sweden) via isourea linkages (Gustafson et al., 1991) and was found to recognize a single band of $\sim 29$ $\mathrm{kDa}$ by immunoblot analysis of total mouse brain homogenate (data not shown). To estimate the difference in I-1 protein concentrations underlying the observed regional variation in staining intensity, spot tests were performed similar to those by Dale et al. (1986). Aliquots $(0.1 \mu \mathrm{l})$ of serial dilutions of recombinant I-1 (13,300 down to $4 \mathrm{~nm}$ in $20 \mu \mathrm{M}$ bovine serum albumin in $10 \mathrm{~mm}$ Tris-HCl buffer) were immobilized on Millipore (Bedford, MA) cellulose ester filter disks and processed for immunocytochemistry along with tissue sections. I-1 spot intensities were compared with staining intensities from different hippocampal regions at dilutions of antibody giving submaximal staining of granule cell bodies. Because the effective light paths cannot be determined, the actual cellular concentrations of I-1 remain unknown. However, a concentration ratio of greater than 10:1 was suggested between the dentate granule cells and the CA1 pyramidal cells, for dendrites as well as for perikarya. Chemicals for which the source is not specifically mentioned were from Fluka or Sigma (St. Louis, MO) and were of the highest available purity.

Slice electrophysiology. Adult wild-type and mutant male mice (30-40 gm) were killed with halothane (Fluothane; AstraZeneca, London, UK). The brain was removed and cooled to $0-4^{\circ} \mathrm{C}$ in artificial CSF (ACSF) of the following composition (in $\mathrm{mM}$ ): $\mathrm{NaCl} 124, \mathrm{KCl} 2, \mathrm{KH}_{2} \mathrm{PO}_{4} 1.25$, $\mathrm{MgSO}_{4} 2, \mathrm{CaCl}_{2} 2, \mathrm{NaHCO}_{3} 26$, and glucose 12 , bubbled with $95 \%$ $\mathrm{O}_{2}-5 \% \mathrm{CO}_{2}, \mathrm{pH} 7.4$. Transverse hippocampal slices $(400 \mu \mathrm{m})$ were cut with a vibratome in cool, bubbled ACSF and placed in an interface chamber exposed to humidified gas and maintained at a temperature of $28-32^{\circ} \mathrm{C}$. To obtain LTP in the dentate gyrus, the induction had to be enhanced by a partial block of $\mathrm{GABA}_{\mathrm{A}}$-mediated inhibition with (-)bicuculline methochloride (6 $\mu \mathrm{M})$ (Tocris Cookson Ltd., Bristol, UK). The resulting hyperexcitability was counteracted by increasing the concentration of $\mathrm{Ca}^{2+}$ and $\mathrm{Mg}^{2+}$ to $4 \mathrm{mM}$. In accordance with earlier reports (Wigström and Gustafsson, 1983, 1985), a series of control experiments showed that this procedure facilitated the induction of LTP in CA1 without significantly changing the magnitude of LTP. However, under these conditions, the percentage increase of the field EPSP (fEPSP) slope in the dentate is somewhat smaller than that observed in CA1. Orthodromic synaptic stimulation was delivered alternately $(0.2 \mathrm{~Hz})$ through two sharp monopolar tungsten electrodes placed in the outer and middle molecular layer in the dentate or in the distal and proximal radiatum layer in the CA1. Extracellular responses were monitored by two glass electrodes (filled with ACSF) in the corresponding synaptic layers. In the CA1 region, the most proximal served as the control and the distal one as the test pathway. In the dentate, alternating between experiments, one of the pathways served as the control, the other as the test pathway. After stable synaptic responses had been obtained in both pathways for at least $15 \mathrm{~min}$, the test pathway was tetanized $(100 \mathrm{~Hz}, 1 \mathrm{sec})$. The tetanic stimulation strength was just above the threshold for generation of a population spike in response to a single test stimulus. This procedure ensured the same effective tetanization strength in all experiments. The synaptic strength was assessed by delivering test stimuli at $10 \mathrm{sec}$ intervals and measuring the slope of the fEPSP in the middle third of its rising phase. Six consecutive responses $(1 \mathrm{~min})$ were averaged and normalized to the mean value obtained 4-7 min before tetanic stimulation. The data were pooled across animals of the same genotype. To avoid serial accumulation of data from one genotype, experiments were performed in pairs, with animals selected from two groups (mutant and wild type), and their group identities were revealed at the end of the experimental series. Data are presented as mean \pm SEM, and statistical significance was evaluated using a two-tailed $t$ test.

In vivo electrophysiology. Male mice, 5-7 months old, were anesthetized with urethane (1.5 gm/kg, i.p.; Sigma) and held in a semistereotaxic apparatus. For experiments in dentate gyrus, a glass recording pipette, filled with ACSF containing pontamine sky blue, was placed $2.0 \mathrm{~mm}$ posterior and $1.9 \mathrm{~mm}$ lateral to bregma and advanced into the dentate gyrus. A bipolar stimulating electrode (Rhodes SNE 100; Clark Electromedical Instruments, Reading, UK) was inserted $3.0 \mathrm{~mm}$ lateral to lambda and advanced into the angular bundle to activate fibers of the perforant path. The depths of the two electrodes were adjusted to produce maximal responses in the granule cell body layer. Constant current stimuli (50 $\mu \mathrm{sec}$ duration, intensity in the range of $70-120 \mu \mathrm{A}$ ) were delivered at intervals of $30 \mathrm{sec}$, and the intensity was adjusted to produce a population spike with an amplitude of $1-2 \mathrm{mV}$. To investigate LTP in area CA1, the recording electrode was positioned $2.0 \mathrm{~mm}$ posterior and $2.0 \mathrm{~mm}$ lateral to bregma on one side, with the stimulating electrode at the same coordinates on the contralateral side. Electrode depths were adjusted to maximize the synaptic response in stratum radiatum. Test stimuli were delivered at $30 \mathrm{sec}$ intervals, and tetanus parameters were those found in previous experiments to be optimal for inducing LTP in mice: in dentate gyrus, six trains of six stimuli at $400 \mathrm{~Hz}$, at twice test intensity, with $100 \mathrm{msec}$ between trains, repeated six times at an interval of $20 \mathrm{sec}$; in area CA1, 50 stimuli at $100 \mathrm{~Hz}$, repeated twice at an interval of $30 \mathrm{sec}$. LTP was assessed for each animal by expressing the mean of the values, obtained 45-50 min after the tetanus, as a percentage of the 10 values obtained before the tetanus. Paired-pulse facilitation, elicited by stimuli of different intensities, delivered over a range of interstimulus intervals, did not reveal any differences between wild-type and mutant mice (data not shown).

Water maze tests. Testing was performed in an open field water maze $2 \mathrm{~m}$ in diameter and filled with opaque water $\left(25 \pm 1^{\circ} \mathrm{C}\right)$ in a laboratory filled with extramaze cues. Paths taken by the mice were monitored with an overhead video camera connected to an image analyzer (HVS Image, Hampton, UK) and an Acorn (Framlingham, UK) computer, running software that sampled the coordinates on-line at $10 \mathrm{~Hz}$ for subsequent automated data analysis. All subjects swam normally and escaped readily onto the platform. Mice were first given four habituation trials without extramaze cues. A $40 \mathrm{~cm}$ flagged platform was used and moved randomly between spaced trials [intertest interval (ITI) of $10 \mathrm{~min}$ ] of $60 \mathrm{sec}$ before the mice, if necessary, were guided to the platform by hand. A further 16 habituation trials (four per day) were given with a flagged $20 \mathrm{~cm}$ platform. Spatial training consisted of 32 trials (four per day) during which the submerged platform remained in a constant position for each mouse. The first 16 trials were with a $30 \mathrm{~cm}$ platform, and the second 16 were with a $20 \mathrm{~cm}$ platform. Trials lasted a maximum of $90 \mathrm{sec}$, followed by an interval of $20 \mathrm{sec}$ on the platform (ITI of $10 \mathrm{~min}$ ). Transfer tests of $60 \mathrm{sec}$ swim were given after these trials. Experimenters were blind as to the genotype of the two animal groups studied. 

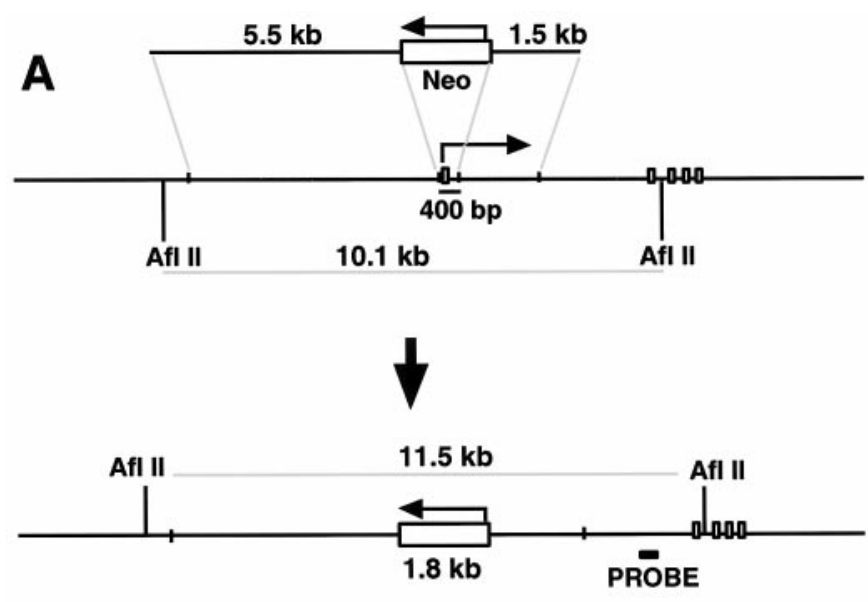

B Southern

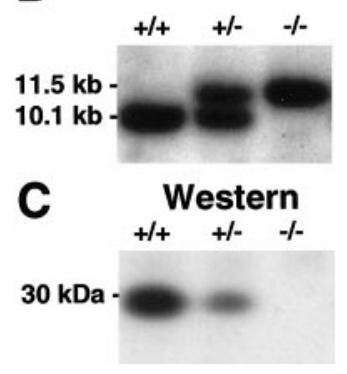

Figure 1. A, Depiction of the mouse $I-1$ genomic locus and the targeting strategy used for gene disruption; a replacement vector was designed to delete a $\sim 400 \mathrm{bp}$ fragment containing the first coding exon of the $I-1$ gene and to replace it with a $\sim 1.8 \mathrm{~kb}$ fragment containing the neomycin resistance gene. Homologous recombination was detected by a reduction in the mobility of a genomic $A f l \mathrm{II}$ restriction fragment because of an increase in size of $\sim 1.4 \mathrm{~kb}$. $B$, Southern blot analysis of genomic tail DNA isolated from an I-1 mutant pedigree and digested with $A f I I$. The probe is depicted in $A$. Wild type, $+/+$; heterozygote, $+/-$; homozygote, $-/-$. $C$, Immunoblot analysis using anti-I-1 antibody. SDS homogenates $(1 \%)$ were prepared from hippocampi taken from animals of the indicated genotype.

\section{RESULTS}

\section{Disruption of the murine l-1 gene}

To address the role of I- 1 in synaptic plasticity, we used gene targeting to prepare a mouse strain lacking I-1 protein. The $I-1$ gene was disrupted in a 129/Ola-derived mouse embryonic stem cell line, using a targeting vector constructed for replacement of the first coding exon of the $I-1$ gene with a neo cassette (Fig. 1A). Homologous recombination was detected by Southern blotting (Fig. 1B). After C57Bl/6J blastocyst injection and embryo transfer into pseudopregnant mothers, chimeric offspring were crossed to $\mathrm{C} 57 \mathrm{Bl} / 6 \mathrm{~J}$ females, and those animals carrying the mutation were crossed to generate heterozygous and homozygous mutants. Analysis of the I-1 protein by immunoblotting of hippocampal $1 \%$ SDS extracts showed a single band migrating with an apparent $M_{\mathrm{r}}$ of $\sim 29 \mathrm{kDa}$ in wild-type mice. Expression of I-1 protein was reduced by approximately half in the heterozygous mutant and abolished in the homozygote (Fig. 1C). I-1 mutant mice appeared to be normal in adult body and organ weights, gross behavior, longevity, and fecundity (data not shown).

\section{I-1 is enriched in dentate granule cells}

Mutant mice showed no staining for I-1 in immunohistochemical analyses of hippocampus (CA1-CA3) and dentate gyrus (Fig.
$2 A$ ). Nissl staining revealed no overt structural abnormality in the mutants (data not shown). In wild-type mice, strong staining for I-1 was seen in dentate gyrus, and much lower levels were detected in the hippocampus (Fig. 2B); this is consistent with previous reports of I- 1 distribution in the rat and primate (Gustafson et al., 1991; Barbas et al., 1993) (but see Sakagami et al., 1994; Lowenstein et al., 1995). I-1 immunoreactivity in both regions decreased gradually from the septal to the temporal pole. Using antibody concentrations that were supersaturating for dentate gyrus, I-1 staining was also detectable in pyramidal cells, including those of CA1. I-1 immunoreactivity in the granule cells was concentrated in the cytoplasm of perikarya, avoiding the nuclei of stained cells. The dendrites and mossy fiber terminal boutons of granule cells were also intensely stained (Fig. 2C,D). Electron microscopy revealed staining in spines protruding from the granule cell dendrites but no staining of afferent boutons in the dentate molecular layer (Fig. $2 E$ ), indicating that I-1 is predominantly postsynaptic at these synapses.

\section{I-1 mutants display a synapse-selective deficit in LTP induction}

In view of the regional differences in the pattern of I-1 expression, we examined electrophysiological responses in hippocampus and dentate gyrus of wild-type and I-1 mutant mice $(3 A, B)$. Neuronal viability in slices prepared from animals of both genotypes was equivalent, and there were no differences in either the stimulation strength necessary to elicit excitatory responses or in the form of evoked responses. The perforant path can be subdivided into a lateral and a medial component, originating in the lateral and medial part of the entorhinal cortex, respectively. The lateral perforant path (lpp) makes excitatory synaptic contacts onto dentate granule cell dendrites in the outer third, whereas the medial perforant path (mpp) forms synapses in the middle third of the molecular layer (Hjorth-Simonsen, 1972; Hjorth-Simonsen and Jeune, 1972). Physiologically, these two pathways can be distinguished in slices, because lpp-granule cell synapses show paired-pulse facilitation, whereas paired stimulation of mppgranule cell synapses predominantly causes depression (McNaughton, 1980; Hanse and Gustafsson, 1992; Colino and Malenka, 1993; Min et al., 1998). The paired-pulse facilitation in the outer molecular layer and the paired-pulse depression in the middle molecular layer, tested at $50 \mathrm{msec}$ interstimulus interval, were not significantly different in the two groups of animals (wild type vs I-1 mutants in lpp, mean \pm SEM, $129 \pm 5 \%, n=7$ vs $134 \pm 6 \%, n=14, p=0.60$; wild type vs I- 1 mutants in mpp, $92 \pm$ $4 \%, n=6$ vs $85 \pm 3 \%, n=13, p=0.11)$.

LTP in the dentate gyrus was elicited in slices by tetanization of either the mpp or lpp fibers. In the mutants, we observed a striking difference in the ability to produce LTP in these two pathways. Tetanization of mpp gave substantial and equally well developed LTP in wild-type and mutant animals (Fig. 3C). At 45 min after tetanization, the values for the slope of the fEPSP in relation to the pretetanic value were $132 \pm 10 \%$ for wild-type $(n=11)$ and $132 \pm 7 \%$ for mutant animals $(n=21)$. When the lateral perforant path was tetanized, the picture was dramatically different (Fig. 3D). Whereas fEPSP measured $137 \pm 5 \%$ in wild-type mice $(n=17)$, the mutants showed only $109 \pm 5 \%(n=$ 32). This remaining value was, however, significantly different from the control input, which showed $98 \pm 2 \%(p=0.03)$. In an attempt to confirm the regulatory role of I-1 during LTP induction in the lpp-granule cell synapses, we tried to re-establish LTP by loading granule cells from mutant mice with I-1 or with 
Figure 2. Immunoperoxidase labeling of I-1 in the hippocampal formation (see large box in Fig. $3 A$ ) of I-1 homozygous mutant and wild-type mice. $A$, In the mutant, there is no immunoreactivity. The darkness in the alveus $(A)$ and the stratum lacunosum-moleculare $(L M)$ is attributable to light scattering by the myelinated fibers abundant in these zones; to be visible, the photomicrograph of $A$ was printed at twice the exposure time for wild type. $B$, In the wild type, the staining in the dentate gyrus, mossy fiber layer in CA3 $(M F)$ terminal zones and $L M$ is much stronger than in other regions. The cellular localization of I-1 in the dentate gyrus dorsal blade is shown by differential interference contrast $(C, D)$ and electron microscopy $(E)$. Granule cell perikarya $(g)$, dendrites (arrows), and mossy fiber boutons (arrowheads) are strongly immunoreactive. $E$, A labeled spine $(s)$ protruding from an immunopositive dendrite (arrow) receives an asymmetric synapse from an immunonegative nerve ending. $A$, Alveus; $H$, hilus; $O$, stratum oriens; $P$, stratum pyramidale; $R$, stratum radiatum; $L M$, stratum lacunosum-moleculare; $M F$, mossy fiber layer in $\mathrm{CA} 3$; $G$, stratum granulare; $\mathrm{Mi}, \mathrm{Mm}, \mathrm{Mo}$, inner, middle, and outer thirds of stratum moleculare of the dentate gyrus. $R$ contains the Schaffer collateral terminals, and $\mathrm{Mo}$ and $\mathrm{Mm}$ contain the terminals of the lateral and medial perforant path, respectively. Asterisks mark the obliterated hippocampal fissure. Scale bars: $A, B, 200 \mu \mathrm{m} ; C, 50 \mu \mathrm{m} ; D, 10$ $\mu \mathrm{m} ; E, 0.5 \mu \mathrm{m}$.
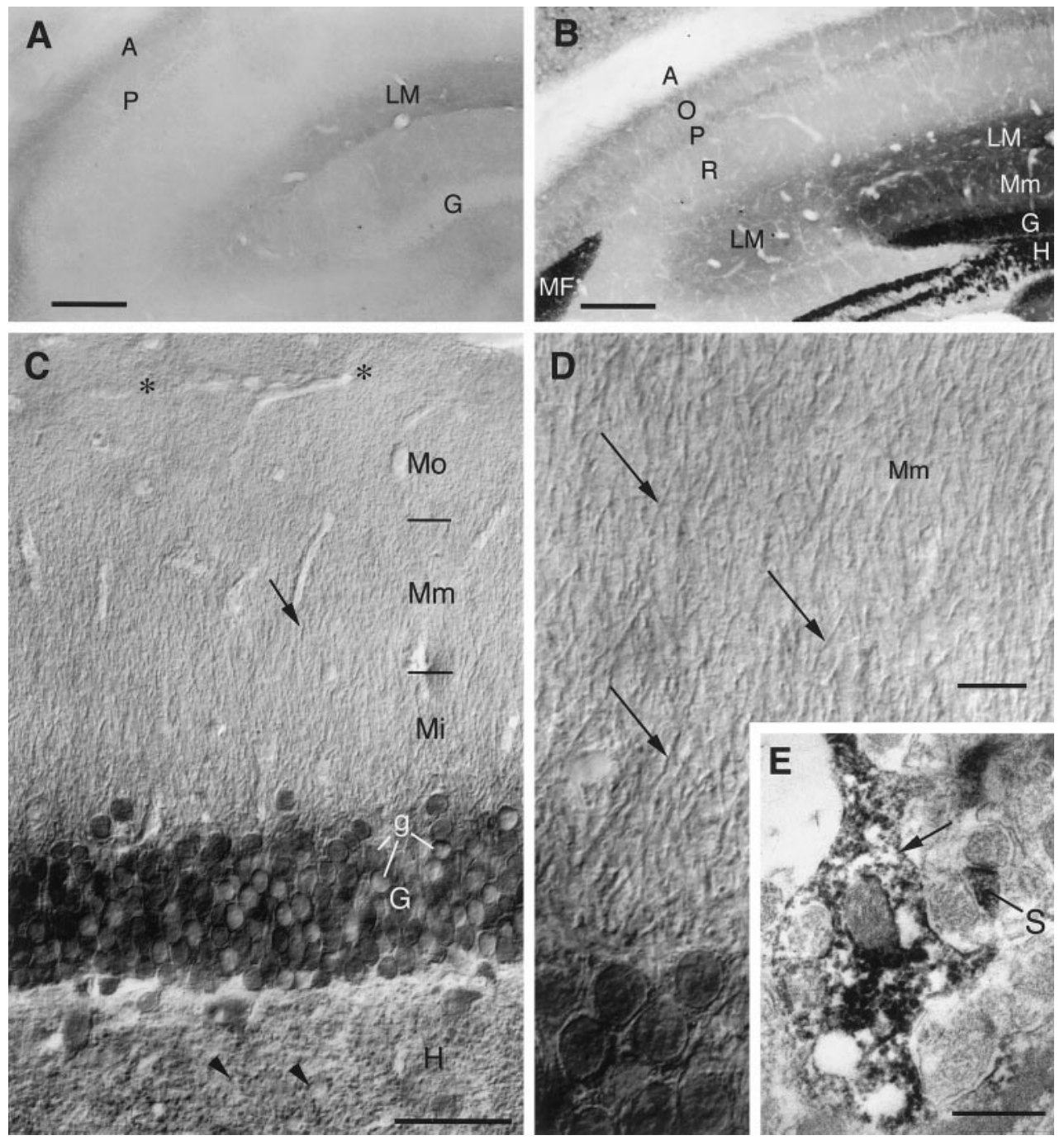

thiophosphorylated I-1. However, this approach, with both sharp electrodes and patch electrodes, was abandoned because of technical difficulties associated with injection into the small mouse granule cells.

Tetanization of stratum radiatum fibers and recording the fEPSP of CA1 pyramidal cells revealed that LTP at these synapses was equally strong in wild-type and I-1 mutant mice (Fig. $3 E)$. The radiatum-CA1 fEPSP in wild-type animals measured $154 \pm 12 \%(n=14)$ of the pretetanic control value 45 min after tetanization. In slices from I-1 mutant mice, the corresponding fEPSP value was $153 \pm 9 \%(n=11)$.

To corroborate these findings, in vivo recordings were made in anesthetized mice. This preparation gave results that were qualitatively similar to those obtained in slices; recordings in CA1 did not reveal any significant difference in LTP [wild type, $120 \pm 5 \%$ $(n=4)$; mutant, $122 \pm 4 \%(n=4)$, measured at $45-50$ min after tetanus]. In the perforant path (Fig. 4), LTP of the fEPSP in dentate gyrus was greatly reduced in I-1 mutant mice, becoming insignificant $(p=0.2)$ at $50 \mathrm{~min}$ [wild type, $115.1 \pm 4.1 \%(n=7)$; mutant, $103.6 \pm 2.5 \%(n=7)$, measured at $45-50 \mathrm{~min}$ after tetanus]. The difference in paired-pulse facilitation seen in vitro cannot be exploited to help distinguish between the two pathways in vivo because both lpp and mpp exhibit paired-pulse facilitation in the intact animal (M. L. Errington, unpublished observations;
McNaughton and Barnes, 1977). We cannot rule out the possibility that both mpp and lpp contribute significantly to test input responses. However, the magnitude of the plasticity deficit observed in vivo indicated that LTP induction in whole brain preparations is at least as sensitive to PP1 activity as it is in slices.

It has been proposed that LTD is associated with enhanced phosphatase activity (Lisman, 1989). This proposal was supported by the observation that pharmacological blockade of PP-1 activity in rat slices prevents NMDA receptor-dependent LTD induction in CA1 (Mulkey et al., 1994). A priori, the I-1 mutants might be expected to exhibit well developed LTD (unless depression was already maximal under basal test conditions). In preliminary experiments, LTD induction in CA1 was similar in wildtype and I-1 mutants (R. Mulkey and R. Malenka, personal communication). We attempted to elicit perforant path LTD in slices using reported stimulation paradigms ( $1 \mathrm{~Hz}$ for $15 \mathrm{~min}$ ) (Trommer et al., 1996). In wild-type animals, LTD failed to appear in two separate groups of animals: postnatal day 16-19 $(n=12)$ and adult $(n=4)$. In the young and the adult groups, the fEPSP slope measured $92 \pm 5$ and $109 \pm 12 \%$, respectively, relative to control levels, $15 \mathrm{~min}$ after cessation of $1 \mathrm{~Hz}$ stimulation. Similar results were observed in mutant animals in which the fEPSP slope after the low-frequency train in the two age groups measured $106 \pm 6(n=11)$ and $115 \pm 7 \%(n=7)$, respectively, 


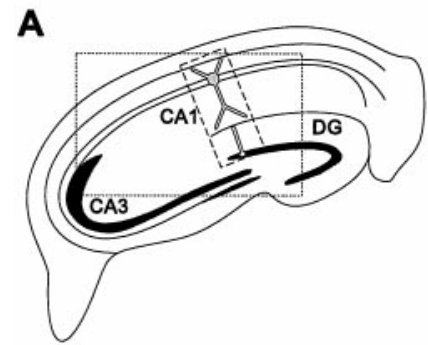

B

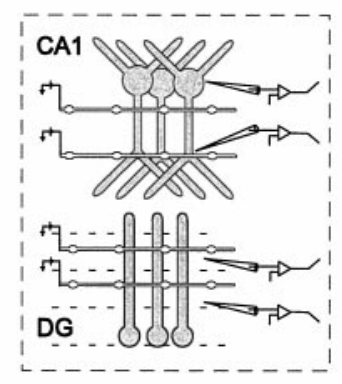

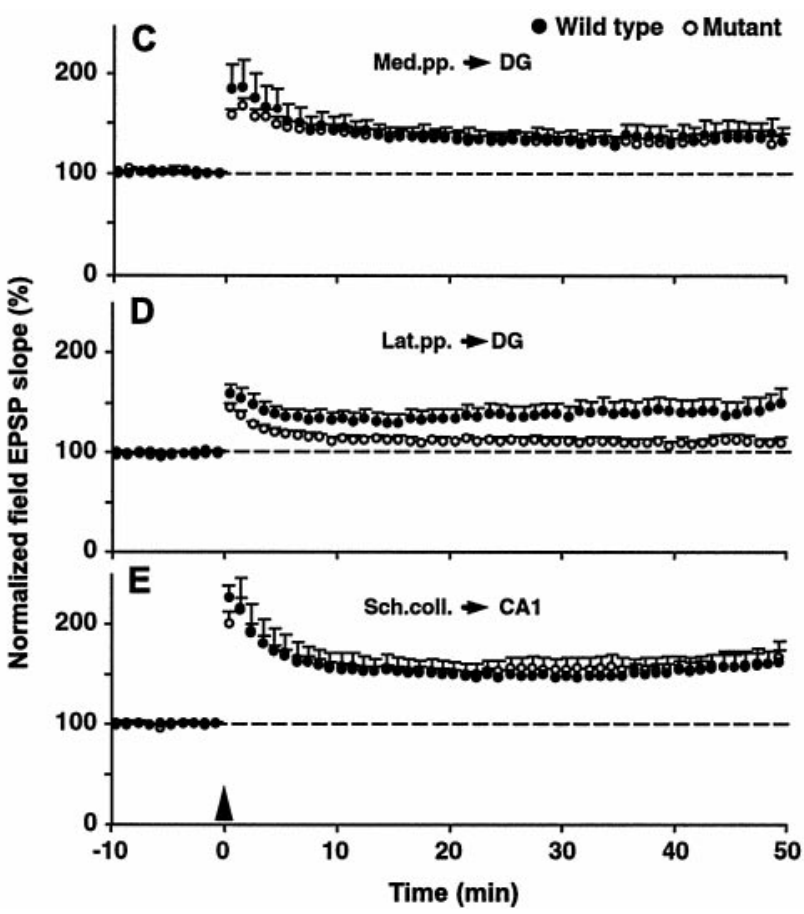

Figure 3. I-1 regulates synaptic plasticity at a subset of synapses. $A$, Schematic of a hippocampal slice. The large box shows the region from which the immunohistochemical section in Figure 2 is taken. The small box indicates the part of CA1 and dentate gyrus in which LTP was studied. $B$, Diagram of stimulating and recording electrode arrangement in the CA1 (top panel) and in the upper blade of the dentate gyrus (bottom panel). $C-E$, Pooled data of the extracellular fEPSP slopes evoked in the wildtype (filled circles) and mutant (open circles) mice in the medial perforant path $(C)$, in the lateral perforant path $(D)$, and in the CA1 region $(E)$. For the sake of clarity, nontetanized control pathway responses are not shown. $A r$ row indicates the time of tetanic stimulation. Vertical bars indicate SEM. relative to control values. In neither the young nor the adult group was the fEPSP slope significantly different between the wild-type and the mutant animals ( $p=0.08$ and $p=0.72$, respectively). There was no observable difference between experiments performed with $2 \mathrm{mM} \mathrm{Ca}^{2+}$ and $2 \mathrm{mM} \mathrm{Mg}^{2+}$ or in solutions with higher calcium concentration $\left(2.5 \mathrm{mM} \mathrm{Ca}^{2+}\right.$ and $\left.1.3 \mathrm{mM} \mathrm{Mg}^{2+}\right)$ or $4 \mathrm{mM} \mathrm{Ca}^{2+}$ and $4 \mathrm{mM} \mathrm{Mg}^{2+}$ with the addition of $6 \mathrm{~mm}$ bicuculline to partially block $\mathrm{GABA}_{\mathrm{A}}$-mediated inhibition.

\section{I-1 mutants perform normally in water maze tests}

The rodent hippocampus plays a critical role in the acquisition and retention of spatial memory (O'Keefe and Nadel, 1978). Projection neurons in the entorhinal cortex provide the main excitatory input to the hippocampus via the perforant path (Hjorth-Simonsen, 1972; Hjorth-Simonsen and Jeune, 1972), and lesions in this relay disrupt spatial learning in both rats (Schenk and Morris, 1985; Whishaw, 1987; Skelton and McNamara, 1992) and mice (Hardman et al., 1997). We therefore examined the

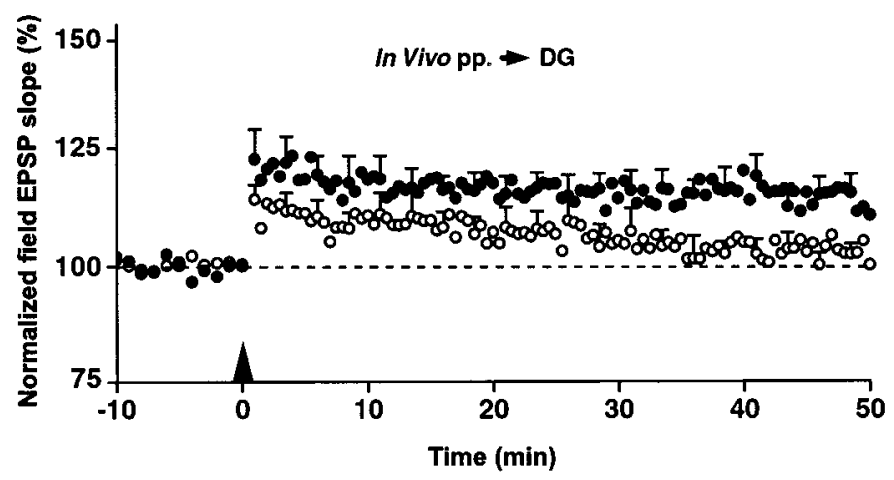

Figure 4. In vivo LTP of the fEPSP in dentate gyrus. After tetanization of the perforant path, LTP in the wild-type group shows significant potentiation, whereas LTP in the mutants declines to baseline over the course of the experiment. Arrow indicates the time of tetanic stimulation. Vertical bars indicate SEM. spatial learning performance of I-1 mutant and wild-type mice in a reference memory task trained in a $2 \mathrm{~m}$ diameter water maze (Morris, 1981). Training was separated into two stages with a smaller platform used for the second stage to increase the difficulty of the task and thus the spatial accuracy required of the mice. Learning occurred over the first $4 \mathrm{~d}$ of training in both mutant and wild-type groups. The second set of trial blocks using the smaller platform produced a similar pattern of results but with a more pronounced effect of trial block and again no difference between mutant and wild-type groups (Fig. 5A). The platforms were removed after both training sets, and animals were examined for any learned preference for the quadrant in which the platform had previously been located. A spatial bias developed for the trained quadrant, and this bias was acquired at a similar rate for mutant and wild-type mice (Fig. 5B). Therefore, both groups of mice learned the water maze task, indicating that intact LTP in the lateral perforant pathway is not a requirement for spatial learning in the water maze.

\section{DISCUSSION}

Abnormalities in hippocampal LTP have been detected in a large number of genetically manipulated mice, and accompanying deficits in spatial learning are most consistently associated with electrophysiological lesions in CA1 (Goda and Stevens, 1996), although this correlation is incomplete (Zamanillo et al., 1999). In I-1 mutant mice, the lpp LTP deficit might be compensated for by intact plasticity in the medial perforant path and/or altered activity at downstream hippocampal synapses. Therefore, a postulated role for lpp LTP in spatial learning cannot be ruled out. Further tests are being performed to analyze the possible contribution of I-1 to additional behavioral parameters.

Earlier reports have emphasized the different anatomical (Hjorth-Simonsen, 1972; Hjorth-Simonsen and Jeune, 1972; Steward, 1976), physiological (McNaughton, 1980; Hanse and Gustafsson, 1992; Colino and Malenka, 1993; Min et al., 1998), and pharmacological (Dahl and Sarvey, 1989; Kahle and Cotman, 

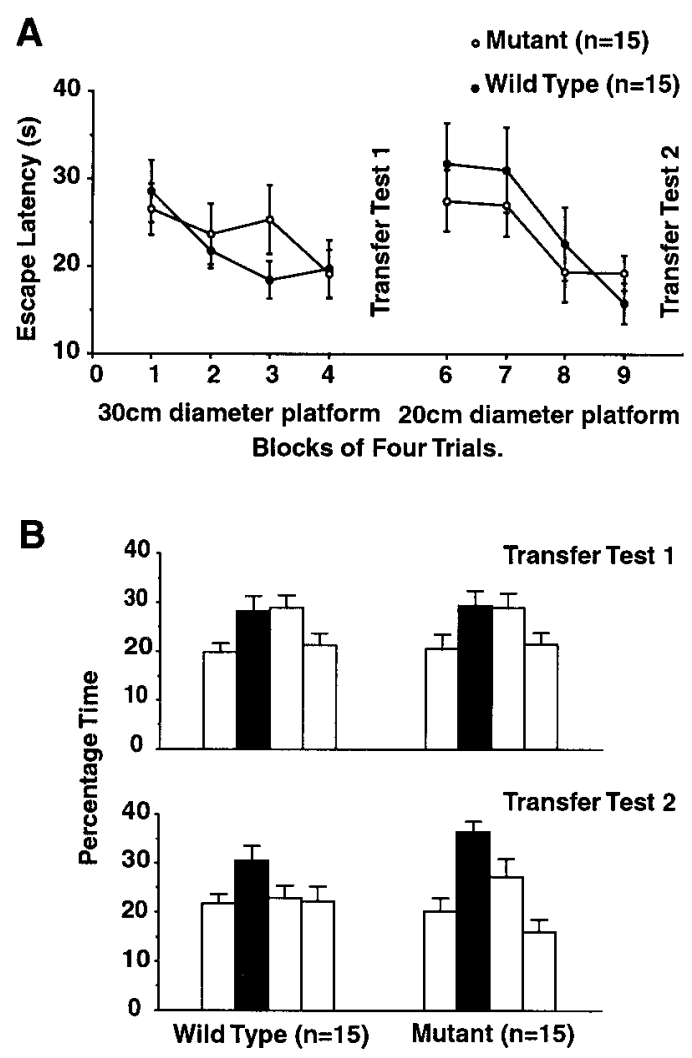

Figure 5. Performance in a water maze test. $A$, Mean escape latencies for mutant and wild-type mice. Initial training was performed using a $30 \mathrm{~cm}$ platform (left). ANOVA revealed an effect of blocks of four trials $\left(F_{(3,84)}=2.76 ; p<0.05\right)$, indicating that learning occurred over the $4 \mathrm{~d}$ of training, whereas no difference was seen between mutant and wild type $(F<1 ; p>0.5)$. After transfer test 1 , subsequent trial blocks were performed using a $20 \mathrm{~cm}$ platform (right), and this produced a similar pattern of results: a more pronounced trial effect $\left(F_{(3,84)}=7.61 ; p<\right.$ $0.001)$ and again no difference between mutant and wild-type groups $(F<$ $1 ; p>0.5) . B$, Percentage time spent in each of the pool quadrants during transfer tests. After the first training set (top panel), an effect of quadrant was seen $\left(F_{(3,84)}=4.63 ; p<0.05\right)$, but a $t$ test revealed that this was between the adjacent left-training and the adjacent right-training quadrants $(p<0.05)$. No difference was found between the training quadrant and the adjacent right quadrant. This suggested that the spatial bias was not yet directed toward the training quadrant alone. No genotype group difference between any of the quadrants was seen $(F<1 ; p>0.3)$. Transfer tests performed after the second set of trials with the $20 \mathrm{~cm}$ platform (bottom panel) indicated that performance had substantially improved. Again, an effect of quadrant was seen $\left(F_{(3,84)}=8.53 ; p<\right.$ $0.001)$. The percentage time spent in the training quadrant was significantly greater relative to both adjacent quadrants $(t$ test: $0.001<p<$ $0.05)$. However, no genotype group difference was found $(F=1 ; p>0.3)$.

1989) characteristics of the mpp and lpp synapses on dentate granule cells. Here, we demonstrate distinct biochemical characteristics underlying synaptic plasticity in the two pathways. LTP induction at both sets of synapses is NMDA receptor-dependent (Hanse and Gustafsson, 1992; Colino and Malenka, 1993; Min et al., 1998), and we show that I-1 is postsynaptically localized in granule cells at both proximal and distal dendrites. However, the development of LTP in the two pathways, targeting the same population of cells, exhibits a differential requirement for protein phosphatase regulation; I-1 is not required in the medial perforant path under the conditions of stimulation used but is important in the lateral perforant path. Unfortunately, attempts to rescue lpp LTP by intracellular injection of dentate granule cells were not successful, mainly because of the difficulty in maintaining a constant and low access resistance with the relatively thin patch pipettes required for such small neurons, in particular with protein-containing electrodes.

What might be the mechanistic basis of the observed mpp-lpp distinction? One possibility would be that in the medial perforant path, synaptic strength is not regulated by PP-1. This seems unlikely given the sensitivity of synaptic plasticity in this pathway to phosphatase inhibition (Wang et al., 1997). A second possibility is that excitability in the more distal dendritic subregions is differentially sensitive to a given phosphatase substrate(s) and thus differentially sensitive to PP-1 regulation via I-1. For example, consider the differential distribution and activity of ion channels found in the apical dendrites of CA1 pyramidal neurons (for review, see Johnston et al., 1999); sodium channels display an increase in the magnitude of slow inactivation with distance from the soma, whereas the density of transient, A-type potassium channels increases along the dendrite. Furthermore, the electrophysiological properties of these channels, and hence dendritic excitability, are modulated by protein phosphorylation cascades. A similar heterogeneity in ion channel function may be present in the dendritic tree of dentate granule cells, with I-1-mediated PP-1 regulation becoming critical in the distal dendrites.

A third possibility that may account for the differential requirement for I-1 at the different synapses may be the involvement of additional PP-1 regulatory subunits. This possibility applies equally to Schaffer collateral-CA1 synapses in which an obligatory role for I-1 in LTP induction appears unlikely, both in view of the relatively weak I-1 expression in these cells and the absence of interference with LTP seen in the I-1 mutants. Several additional PP-1 regulatory candidates exist: the PP-1 targeting protein spinophilin is highly enriched in dendritic spines and mediates the control of AMPA channel activity in striatal neurons (Allen et al., 1997; Yan et al., 1999); neurabin is a structurally related PP-1 binding protein that is also present at synapses (Nakanishi et al., 1997; McAvoy et al., 1999). In addition, the NMDA receptor binding protein yotiao targets both PP-1 and PKA to the NMDA receptor, thereby modulating receptor activity (Westphal et al., 1999). The current challenge is to identify the means by which calcium influx might be coupled to alterations in the activity of PP-1 as mediated by these newly characterized regulatory subunits. Preliminary studies indicate that the association of PP-1 with neurabin may be regulated by the cAMP pathway (McAvoy et al., 1999).

\section{REFERENCES}

Allen PB, Ouimet CC, Greengard P (1997) Spinophilin, a novel protein phosphatase 1 binding protein localized to dendritic spines. Proc Natl Acad Sci USA 94:9956-9961.

Barbas H, Gustafson EL, Greengard P (1993) Comparison of the immunocytochemical localization of DARPP-32 and I-1 in the amygdala and hippocampus of the rhesus monkey. J Comp Neurol 334:1-18.

Bito H, Deisseroth K, Tsien RW (1996) CREB phosphorylation and dephosphorylation: a $\mathrm{Ca}^{2+}$ - and stimulus duration-dependent switch for hippocampal gene expression. Cell 87:1203-1214.

Blank T, Nijholt I, Teichert U, Kugler H, Behrsing H, Fienberg A, Greengard P, Spiess J (1997) The phosphoprotein DARPP-32 mediates cAMP-dependent potentiation of striatal $N$-methyl-D-aspartate responses. Proc Natl Acad Sci USA 94:14859-14864.

Bliss TVP, Collingridge GL (1993) A synaptic model of memory: longterm potentiation in the hippocampus. Nature 361:31-39.

Blitzer RD, Wong T, Nouranifar R, Iyengar R, Landau EM (1995) Postsynaptic cAMP pathway gates early LTP in hippocampal CA1 region. Neuron 15:1403-1414.

Blitzer RD, Connor JH, Brown GP, Wong T, Shenolikar S, Iyengar R, 
Landau EM (1998) Gating of CaMKII by cAMP-regulated protein phosphatase activity during LTP. Science 280:1940-1942.

Colino A, Malenka RC (1993) Mechanisms underlying induction of long-term potentiation in rat medial and lateral perforant paths in vitro. J Neurophysiol 69:1150-1159.

Dahl D, Sarvey JM (1989) Norepinephrine induces pathway-specific long-lasting potentiation and depression in the hippocampal dentate gyrus. Proc Natl Acad Sci USA 86:4776-4780.

Dale N, Ottersen OP, Roberts A, Storm-Mathisen J (1986) Inhibitory neurones of a motor pattern generator in Xenopus revealed by antibodies to glycine. Nature 324:255-257.

Elbrecht A, DiRenzo J, Smith RG, Shenolikar S (1990) Molecular cloning of protein phosphatase inhibitor-1 and its expression in rat and rabbit tissues. J Biol Chem 265:13415-13418.

Goda Y, Stevens CF (1996) Synaptic plasticity: the basis of particular types of learning. Curr Biol 6:375-378.

Greengard P, Allen PB, Nairn AC (1999) Beyond the dopamine receptor: the DARPP-32/protein phosphatase-1 cascade. Neuron 23:435-447.

Gustafson EL, Girault JA, Hemmings Jr HC, Nairn AC, Greengard P (1991) Immunocytochemical localization of phosphatase inhibitor-1 in rat brain. J Comp Neurol 310:170-188.

Hanse E, Gustafsson B (1992) Long-term potentiation and field EPSPs in the lateral and medial perforant paths in the dentate gyrus in vitro: a comparison. Eur J Neurosci 4:1191-1201.

Hardman R, Evans DJ, Fellows L, Hayes B, Rupniak HT, Barnes JC, Higgins GA (1997) Evidence for recovery of spatial learning following entorhinal cortex lesions in mice. Brain Res 758:187-200.

Hjorth-Simonsen A (1972) Projection of the lateral part of the entorhinal area to the hippocampus and fascia dentata. J Comp Neurol 146:219-232.

Hjorth-Simonsen A, Jeune B (1972) Origin and termination of the hippocampal perforant path in the rat studied by silver impregnation. J Comp Neurol 144:215-232.

Johnston D, Hoffman DA, Colbert CM, Magee JC (1999) Regulation of back-propagating action potentials in hippocampal neurons. Curr Opin Neurobiol 9:288-292.

Kahle JS, Cotman CW (1989) Carbachol depresses synaptic responses in the medial but not the lateral perforant path. Brain Res 482:159-163.

Lisman J (1989) A mechanism for the Hebb and the anti-Hebb processes underlying learning and memory. Proc Natl Acad Sci USA 86:9574-9578.

Lowenstein PR, Shering AF, MacDougall LK, Cohen P (1995) Immunolocalisation of protein phosphatase inhibitor-1 in the cerebral cortex of the rat, cat and ferret. Brain Res 676:80-92.

McAvoy T, Allen PB, Obaishi H, Nakanishi H, Takai Y, Greengard P, Nairn AC, Hemmings Jr HC (1999) Regulation of neurabin I interaction with protein phosphatase 1 by phosphorylation. Biochemistry 38:12943-12949.

McNaughton BL (1980) Evidence for two physiologically distinct perforant pathways to the fascia dentata. Brain Res 199:1-19.

McNaughton BL, Barnes CA (1977) Physiological identification and analysis of dentate granule cell responses to stimulation of the medial and lateral perforant pathways in the rat. J Comp Neurol 175:439-454.

Min MY, Asztely F, Kokaia M, Kullmann DM (1998) Long-term potentiation and dual-component quantal signaling in the dentate gyrus. Proc Natl Acad Sci USA 95:4702-4707.

Morris RGM (1981) Spatial localisation does not require the presence of local cues. Learn Motiv 12:239-260.

Mulkey RM, Endo S, Shenolikar S, Malenka RC (1994) Involvement of a calcineurin/inhibitor-1 phosphatase cascade in hippocampal longterm depression. Nature 369:486-488.

Nakanishi H, Obaishi H, Satoh A, Wada M, Mandai K, Satoh K, Nishioka H, Matsuura Y, Mizoguchi A, Takai Y (1997) Neurabin: a novel neural tissue-specific actin filament-binding protein involved in neurite formation. J Cell Biol 139:951-961.

O'Keefe J, Nadel L (1978) The hippocampus as a cognitive map. Oxford: Oxford UP.

Ouimet CC, da Cruz e Silva EF, Greengard P (1995) The alpha and gamma 1 isoforms of protein phosphatase 1 are highly and specifically concentrated in dendritic spines. Proc Natl Acad Sci USA 92:3396-3400.

Sakagami H, Ebina K, Kondo H (1994) Localization of phosphatase inhibitor-1 mRNA in the developing and adult rat brain in comparison with that of protein phosphatase-1 mRNAs. Mol Brain Res 25:7-18.

Schenk F, Morris RG (1985) Dissociation between components of spatial memory in rats after recovery from the effects of retrohippocampal lesions. Exp Brain Res 58:11-28.

Skelton RW, McNamara RK (1992) Bilateral knife cuts to the perforant path disrupt spatial learning in the Morris water maze. Hippocampus 2:73-80.

Snyder GL, Fienberg AA, Huganir RL, Greengard P (1998) A dopamine/D1 receptor/protein kinase A/dopamine- and cAMP-regulated phosphoprotein $(\mathrm{Mr} 32 \mathrm{kDa}) /$ protein phosphatase-1 pathway regulates dephosphorylation of the NMDA receptor. J Neurosci 18:10297-12303.

Steward O (1976) Topographic organization of the projections from the entorhinal area to the hippocampal formation of the rat. J Comp Neurol 167:285-314.

Strack S, Barban MA, Wadzinski BE, Colbran RJ (1997) Differential inactivation of postsynaptic density-associated and soluble $\mathrm{Ca}^{2+}$ / calmodulin-dependent protein kinase II by protein phosphatases 1 and 2A. J Neurochem 68:2119-2128.

Thompson S, Clarke AR, Pow AM, Hooper ML, Melton DW (1989) Germ line transmission and expression of a corrected HPRT gene produced by gene targeting in embryonic stem cells. Cell 56:313-321.

Tokuda M, Hatase O (1998) Regulation of neuronal plasticity in the central nervous system by phosphorylation and dephosphorylation. Mol Neurobiol 17:137-156.

Trommer BL, Liu YB, Pasternak JF (1996) Long-term depression at the medial perforant path-granule cell synapse in developing rat dentate gyrus. Dev Brain Res 96:97-108.

Tybulewicz VL, Crawford CE, Jackson PK, Bronson RT, Mulligan RC (1991) Neonatal lethality and lymphopenia in mice with a homozygous disruption of the c-abl proto-oncogene. Cell 65:1153-1163.

Wang Y, Wu J, Rowan MJ, Anwyl R (1997) Conditions for the induction of long-term potentiation and long-term depression by conjunctive pairing in the dentate gyrus in vitro. J Neurophysiol 78:2569-2573.

Westphal RS, Tavalin SJ, Lin JW, Alto NM, Fraser ID, Langeberg LK, Sheng M, Scott JD (1999) Regulation of NMDA receptors by an associated phosphatase-kinase signaling complex. Science 285:93-96.

Whishaw IQ (1987) Hippocampal, granule cell and CA3-4 lesions impair formation of a place learning-set in the rat and induce reflex epilepsy. Behav Brain Res 24:59-72.

Wigström H, Gustafsson B (1983) Large long-lasting potentiation in the dentate gyrus in vitro during blockade of inhibition. Brain Res 275:153-158.

Wigström H, Gustafsson B (1985) Facilitation of hippocampal longlasting potentiation by GABA antagonists. Acta Physiol Scand 125:159-172.

Yan Z, Hsieh-Wilson L, Feng J, Tomizawa K, Allen PB, Fienberg AA, Nairn AC, Greengard P (1999) Protein phosphatase 1 modulation of neostriatal AMPA channels: regulation by DARPP-32 and spinophilin. Nat Neurosci 2:13-17.

Zamanillo D, Sprengel R, Hvalby Ø, Jensen V, Burnashev N, Rozov A, Kaiser KM, Köster HJ, Borchardt T, Worley P, Lübke J, Frotscher M, Kelly PH, Sommer B, Andersen P, Seeburg PH, Sakmann B (1999) Importance of AMPA receptors for hippocampal synaptic plasticity but not for spatial learning. Science 284:1805-1811. 